\title{
Fecal Occult Blood Testing Beliefs and Practices of U.S. Primary Care Physicians: Serious Deviations from Evidence-Based Recommendations
}

\author{
Marion R. Nadel, $P h D^{7}$, Zahava Berkowitz, $M S P H^{7}$, Carrie N. Klabunde, $P h D^{2}$, \\ Robert A. Smith, $P h D^{3}$, Steven S. Coughlin, $P h D^{1,4}$, and Mary C. White, ScD ${ }^{1}$
}

'Division of Cancer Prevention and Control, Centers for Disease Control and Prevention, Atlanta, GA, USA; ${ }^{2}$ Division of Cancer Control and Population Sciences, National Cancer Institute, Bethesda, MD, USA; ${ }^{3}$ Cancer Control Science Department, American Cancer Society, Atlanta, GA, USA; ${ }^{4}$ Department of Veterans Affairs, Environmental Epidemiology Service, Washington, DC, USA.

BACKGROUND: Fecal occult blood testing (FOBT) is an important option for colorectal cancer screening that should be available in order to achieve high population screening coverage. However, results from a national survey of clinical practice in 1999-2000 indicated that many primary care physicians used inadequate methods to implement FOBT screening and follow-up.

OBJECTIVE: To determine whether methods to screen for fecal occult blood have improved, including the use of newer more sensitive stool tests.

DESIGN: Cross-sectional national survey of primary care physicians.

PARTICIPANTS: Participants consisted of 1,134 primary care physicians who reported ordering or performing FOBT in the 2006-2007 National Survey of Primary Care Physicians' Recommendations and Practices for Cancer Screening.

MAIN MEASURES: Self-reported data on details of FOBT implementation and follow-up of positive results. RESULTS: Most physicians report using standard guaiac tests; higher sensitivity guaiac tests and immunochemical tests were reported by only $22.0 \%$ and $8.9 \%$, respectively. In-office testing, that is, testing of a single specimen collected during a digital rectal examination in the office, is still widely used although inappropriate for screening: $24.9 \%$ of physicians report using only in-office tests and another 52.9\% report using both in-office and home tests. Recommendations improved for follow-up after a positive test: fewer physicians recommend repeating the FOBT $(17.8 \%)$ or using tests other than colonoscopy for the diagnostic work-up (6.6\%). Only $44.3 \%$ of physicians who use home tests have reminder systems to ensure test completion and return.

CONCLUSIONS: Many physicians continue to use inappropriate methods to screen for fecal occult blood. Intensified efforts to inform physicians of recommended technique and promote the use of tracking systems are needed.

Received September 18, 2009

Revised February 8, 2010

Accepted February 15, 2010

Published online April 10, 2010
KEY WORDS: colorectal cancer; cancer screening; primary care; quality of care; fecal occult blood test.

$\mathrm{J}$ Gen Intern Med 25(8):833-9

DOI: $10.1007 / \mathrm{s} 11606-010-1328-7$

(C) The Author(s) 2010. This article is published with open access at Springerlink.com

\section{INTRODUCTION}

For more than a decade, major national organizations have strongly recommended routine screening for colorectal cancer, the second leading cause of cancer-related death in the U.S. ${ }^{1-10}$ Although screening rates have increased, they remain considerably lower than the rates for other recommended cancer screening tests. ${ }^{11}$

Until recently the most widely used of the recommended screening options was fecal occult blood testing (FOBT), shown to be effective in reducing colorectal cancer incidence and mortality in randomized controlled trials. ${ }^{12-15}$ However, its effectiveness in general clinical practice depends on the degree to which health professionals follow recommended testing guidelines. A national survey of primary care physicians conducted in 1999-2000 revealed serious problems in the way many physicians in the U.S. implemented FOBT in practice. ${ }^{16}$ Rather than relying on the multiple-specimen home test that was evaluated in the trials, $74 \%$ of physicians reported performing in-office tests, that is, testing of a single stool specimen collected in the office during digital rectal examination. The in-office test has been shown to be a very poor test that misses $95 \%$ of advanced neoplasia. ${ }^{17}$ The survey also showed that follow-up of positive FOBTs was often inconsistent with recommended standards of practice. Nearly $30 \%$ of physicians recommended repeating FOBT after a positive result rather than referring the patient for colonoscopy. Sigmoidoscopy, rather than colonoscopy, was commonly recommended to work up abnormal findings. Analysis of data from a contemporaneous survey of adults, the 2000 National Health Interview Survey (NHIS), showed similar results. These observations led one commentator to speculate that, after many years of FOBT testing in the population, colorectal cancer mortality rates might be considerably lower today if more physicians had followed recommended testing and follow-up methods. ${ }^{18}$

Since 2000, screening patterns have changed considerably, with colonoscopy becoming the most commonly used colorectal 
cancer screening test. ${ }^{11,19,20}$ However, FOBT is still recommended by most primary care physicians. ${ }^{20}$ It is preferred by a significant fraction of adults ${ }^{21}$ and is the only test available to those with insufficient insurance coverage or who live in areas with limited high quality endoscopic services. Using data from the National Survey of Primary Care Physicians' Recommendations and Practices for Cancer Screening, conducted in late 2006 and early 2007, we reported in a recent paper the tests that physicians recommend for colorectal cancer screening and the office systems they use to support screening. We found that $95 \%$ of primary care physicians routinely recommend colonoscopy and $80 \%$ routinely recommend FOBT for colorectal cancer screening. ${ }^{20}$ Indeed, FOBT needs to remain part of every practice's menu of screening options if high population coverage is to be achieved. Growing evidence that the newer FOBTs are superior to the standard guaiac test used in the original screening trials suggests that FOBT may be a more effective screening option now than when screening guidelines were first issued. ${ }^{22,23}$

Have physicians' methods for implementing FOBT improved? Since 2000, more recent versions of national screening guidelines have explicitly recommended against in-office FOBT and against repeating FOBT in response to an initial positive finding. ${ }^{5-7,9}$ Billing codes were changed to emphasize that only home tests are appropriate for screening. ${ }^{24}$

We report here an in-depth analysis of FOBT practices using data from the 2006-2007 primary care physician survey to assess whether there has been improvement in the methods physicians use to implement FOBT and their beliefs about and use of the newer fecal occult blood tests.

\section{METHODS}

The National Cancer Institute (NCI) collaborated with the Centers for Disease Control and Prevention (CDC) and the Agency for Healthcare Research and Quality (AHRQ) to survey a nationally representative sample of primary care physicians between September 2006 and May 2007. The American Medical Association's Physician Masterfile was used to form the sample, which included family practitioners, general practitioners, general internists and obstetrician-gynecologists. A systematic, stratified random sample was selected with the four specialty types as the sampling strata. Eligible respondents were non-federal, officebased physicians 75 years of age or younger who had an active license to practice medicine and whose major professional activity was patient care. Additional details of the sampling and survey methods have been described elsewhere. ${ }^{20}$

Questions about physicians' colorectal cancer screening recommendations and practices were specific to asymptomatic, average-risk patients and were similar to those used in the 1999-2000 survey. Physicians were asked about their perceptions of the effectiveness of guaiac and immunochemical FOBT in reducing colorectal cancer mortality. They were also asked, 'For the majority of your patients, by what means do you conduct FOBT for screening purposes: complete a single FOBT card in the office during a digital rectal exam, give or mail patients FOBT kits to complete at home, both of the above, or do not use FOBT in my practice.' Physicians were then asked which procedure or procedures they usually recommended to healthy, average-risk patients as an initial follow-up test after positive results on FOBT. Physicians who reported repeating the FOBT were asked if they stop the workup if the second FOBT is negative. The questionnaire underwent cognitive interviewing and survey materials were pre-tested among a small, randomlyselected sample of primary care physicians. The survey questionnaire is available at: http://healthservices.cancer. gov/surveys/screening_rp/.

We assessed follow-up of positive FOBT results in two steps, as before. ${ }^{16}$ Among the 1,134 physicians who ordered or performed FOBT at least once per month, we first looked at whether they recommended repeating the FOBT. We then examined which tests were recommended for the diagnostic work-up. At this second step, we did not include respondents who only reported repeated FOBT $(n=104)$, those who only indicated that they referred patients to another physician for follow-up of positive FOBT results $(n=28)$ and those whose response we could not classify $(n=3)$.

For the bivariate analyses of data, we performed a loglikelihood chi-square test for the association between each of the various physician or physicians' practice characteristics and the outcome variables, i.e., percentage of physicians who use inoffice tests (Table 2) and percentage of physicians who repeat FOBT after abnormal results (Table 3). For the multivariate analyses, we performed logistic regression using the Wald chisquare test to test the association between each physician or practice characteristic and each of the outcomes described above while controlling for all other variables in the respective table. We computed predictive margins (adjusted percentages), a type of direct standardization that averages the predicted values from the logistic regression models over the covariate distribution in the population, allowing comparisons across categories of the variables included in the models. ${ }^{25}$ To permit generalization of the results of all analyses to the U.S. population of practicing primary care physicians, we used sampling weights that account for the probability of selection and non-response. We used the SAS statistical package, version 9.1.3 (SAS Institute, Inc., Cary, North Carolina) ${ }^{26}$, and SUDAAN, version 9 (Research Triangle Institute, Research Triangle Park, North Carolina) ${ }^{27}$ to compute estimates, confidence intervals and $P$ values.

This study was determined to be exempt from review by the institutional review boards at the NCI and CDC.

\section{RESULTS}

\section{Description of Respondents}

A total of 1266 physicians responded to the survey. The absolute response rate was $69.3 \%$. The cooperation rate, which measures participation among contacted physicians, was $75.0 \%$. Ninety percent of respondents $(n=1134)$ indicated that they ordered or performed FOBT as a colorectal cancer screening method for asymptomatic average-risk patients at least once during a typical month. The results reported below are based on these 1134 physicians, whose personal and practice characteristics are shown by specialty (Table 1).

\section{Guaiac-Based and Immunochemical FOBT: Perceived Effectiveness and Use}

A total of $85.4 \%$ of physicians believed that guaiac-based tests were somewhat or very effective in reducing colorectal cancer 
Table 1. Characteristics of Primary Care Physicians and Their Practice Settings by Physician's Specialty ${ }^{a}$

\begin{tabular}{|c|c|c|c|c|c|}
\hline \multirow[t]{2}{*}{ Variable } & \multirow{2}{*}{$\begin{array}{l}\text { Family Practice } \\
(n=452) \\
\%\end{array}$} & \multirow{2}{*}{$\begin{array}{l}\text { General practice } \\
(n=61) \\
\%\end{array}$} & \multirow{2}{*}{$\begin{array}{l}\text { Obstetrics/Gynecology } \\
(n=249) \\
\%\end{array}$} & \multirow{2}{*}{$\begin{array}{l}\text { Internal Medicine } \\
(n=372) \\
\%\end{array}$} & \multirow{2}{*}{$\begin{array}{l}\text { Total }(n=1134) \\
\%\end{array}$} \\
\hline & & & & & \\
\hline \multicolumn{6}{|l|}{ Physician Characteristics } \\
\hline Gender (male) & 69.1 & 88.5 & 61.9 & 68.6 & 68.4 \\
\hline \multicolumn{6}{|l|}{ Age (years) } \\
\hline$<40$ & 22.7 & 0.0 & 17.5 & 20.0 & 20.0 \\
\hline $40-49$ & 30.0 & 10.0 & 28.8 & 33.2 & 30.3 \\
\hline $50-59$ & 34.6 & 32.6 & 32.4 & 29.7 & 32.4 \\
\hline$\geq 60$ & 12.7 & 57.4 & 21.4 & 17.1 & 17.4 \\
\hline \multicolumn{6}{|l|}{ Race/ethnicity } \\
\hline Non-Hispanic White & 78.5 & 75.5 & 74.1 & 64.7 & 72.6 \\
\hline Non-Hispanic Black & 2.8 & 0.0 & 5.4 & 4.4 & 3.7 \\
\hline Hispanic & 4.2 & 8.4 & 6.0 & 6.2 & 5.4 \\
\hline Non-Hispanic Asian & 10.0 & 14.6 & 11.7 & 20.5 & 14.3 \\
\hline Other $^{\mathrm{b}}$ & 4.6 & 1.5 & 2.8 & 4.2 & 4.0 \\
\hline Board certified (yes) & 85.7 & 3.0 & 84.0 & 78.9 & 79.9 \\
\hline Medical school affiliation (yes) & 34.2 & 17.5 & 43.7 & 33.7 & 35.0 \\
\hline \multicolumn{6}{|l|}{ Practice Characteristics } \\
\hline \multicolumn{6}{|l|}{ Metropolitan location } \\
\hline Urban & 73.9 & 65.2 & 88.3 & 87.9 & 81.1 \\
\hline Large rural city/town & 12.2 & 19.8 & 9.1 & 8.5 & 10.6 \\
\hline Small rural city/town & 13.9 & 15.0 & 2.6 & 3.6 & 8.3 \\
\hline \multicolumn{6}{|l|}{ Practice type } \\
\hline Single specialty & 75.7 & 80.3 & 75.8 & 66.7 & 72.6 \\
\hline Multi-specialty & 19.7 & 11.6 & 21.2 & 30.9 & 23.8 \\
\hline Other/missing & 4.6 & 8.1 & 2.9 & 2.4 & 3.7 \\
\hline \multicolumn{6}{|c|}{ Number of physicians in Primary location } \\
\hline 1 & 24.7 & 54.5 & 23.1 & 26.5 & 26.2 \\
\hline $2-5$ & 47.4 & 28.4 & 34.0 & 39.7 & 42.1 \\
\hline $6-15$ & 19.6 & 13.9 & 26.5 & 20.9 & 21.0 \\
\hline$\geq 16$ & 8.3 & 3.2 & 13.5 & 12.9 & 10.7 \\
\hline
\end{tabular}

${ }^{a}$ Percentages are weighted to account for the survey design. Percentages may not add to $100 \%$ because of rounding

${ }^{b}$ Other includes American Indian/Alaska Native, Native Hawaiian/Other Pacific Islander, multiple races, other race and unknown or missing.

Variables with missing data (<10 records): medical school affiliation, number of physicians in primary location

mortality in average-risk patients; $54.1 \%$ believed immunochemical tests were effective; $38.4 \%$ reported not knowing about the effectiveness of the immunochemical tests (Fig. 1).

Use of standard guaiac-based cards, such as Hemoccult II (Beckman Coulter, Fullerton, California), was reported by $61.1 \%$ (95\% CI, 57.8\%-64.3\%) of physicians. Higher-sensitivity FOBTs, such as Hemoccult SENSA (Beckman Coulter, Fullerton, California), were used by $22.0 \%$ (CI, 19.8\%-24.5\%). Fecal immunochemical tests were used by $8.9 \%$ (CI, 7.3\%-10.9\%). A total of $14.7 \%$ (CI, $12.5 \%-17.2 \%$ ) of physicians did not know the brand of test they used.

\section{Method of Conducting FOBT}

Of the physicians who reported ordering or performing FOBT for screening at least once per month, $22.2 \%$ (95\% CI, 19.7\%$24.9 \%$ ) used home-based FOBT exclusively for the majority of their patients, $24.9 \%$ (CI, 22.3\%-27.6\%) used in-office FOBT exclusively, and 52.9\% (CI, 49.8\%-56.1\%) used both home and in-office tests. Obstetrician-gynecologists were most likely to use in-office tests exclusively (Fig. 2). Table 2 shows the relationship between various physician characteristics and use of in-office tests, either exclusively or in addition to home tests. Physicians working in solo practices were more likely to use in-office tests than physicians working in practices with other physicians. Physicians who graduated from medical school longer ago were more likely to use in-office tests than those who graduated more recently, although the difference was not statistically significant after adjustment for the key demographic and practice variables listed. There was little variation by physician gender, urban vs. rural practice location, or affiliation with a medical school (data not shown).

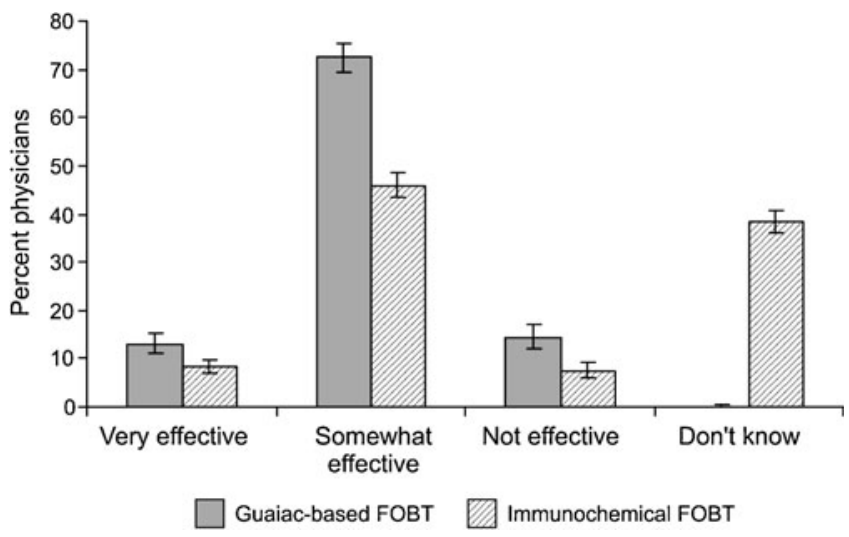

Figure 1. Perceived effectiveness of guaiac-based FOBT* and immunochemical FOBT ${ }^{*}$. ${ }^{\text {FOBT }}=$ fecal occult blood test. Note: Vertical lines within bars indicate $95 \%$ confidence intervals around percentages. 


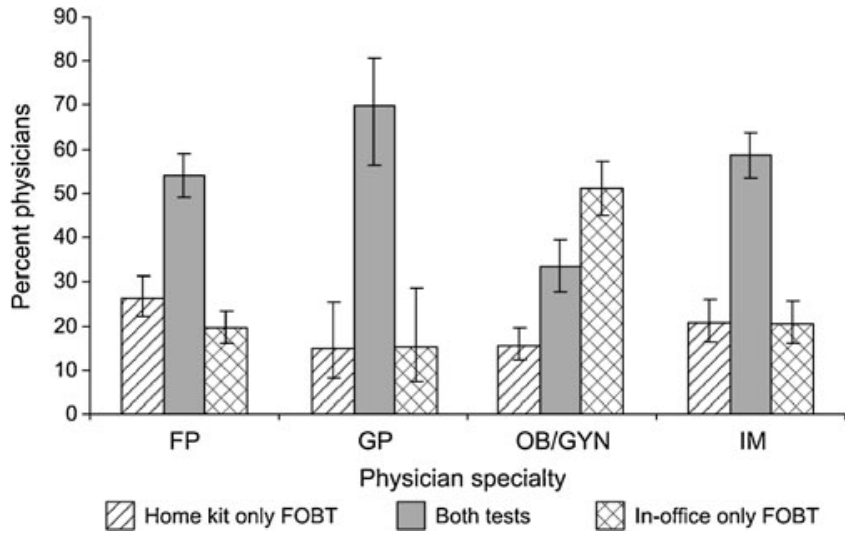

Figure 2. Method of conducting FOBT $^{*}$ for screening, by physician specialty. ${ }^{*} \mathrm{FOBT}=$ fecal occult blood test; FP = family physician; $\mathrm{GP}=$ general practitioner; $\mathrm{OB} / \mathrm{GYN}=$ obstetrician gynecologist;

IM = internist. Note: Vertical lines within bars indicate $95 \%$ confidence intervals around percentages.

\section{Follow-up of Positive FOBT Results}

Repeating the FOBT. Overall, $17.8 \%$ of physicians recommended repeating the FOBT as the initial follow-up step to a positive FOBT (Table 3). Of the physicians who repeated FOBT, 28.8\% (95\% CI, 22.9\%-35.4\%) reported stopping the work-up when the second FOBT was negative and $71.2 \%$ (CI, 64.6\%-77.1\%) reported not stopping the work-up (data not shown).

Physicians who graduated from medical school before 1978 were more likely to recommend repeating the FOBT than physicians who graduated more recently. Physicians in solo practice were more likely to repeat the FOBT than physicians in larger practices, although the difference was not statistically significant after adjustment for the other physician characteristics listed. In contrast to physicians who exclusively used home tests, those who used only in-office tests were more than twice as likely to repeat the FOBT. Physicians who were not board-certified were more likely to repeat the test.

Diagnostic Work-Up. Among the 999 physicians who reported follow-up tests other than repeated FOBT, colonoscopy alone was recommended by $93.4 \%$ (95\% CI, 91.9\%-94.6\%). A total of $4.6 \%$ (CI, 3.5\%-6.0\%) of physicians recommended sigmoidoscopy alone or sigmoidoscopy and/or colonoscopy. Physicians who were not board-certified were the most likely to recommend follow-up other than colonoscopy alone (16.5\%; CI, 11.8\%-22.6\%) (data not shown).

\section{Use of Reminder Systems}

When asked if they had a mechanism to ensure that patients completed and returned home tests, 44.3\% (95\% CI, 41.0\%$47.6 \%$ ) of physicians who used home tests responded affirmatively. Chart reminders or other office systems were reported by $29.7 \%$ (CI, $26.6 \%-33.1 \%$ ), telephone reminders by $13.3 \%$ (CI, $11.3 \%-15.5 \%$ ) and mail reminders by $7.2 \%$ (CI, $5.5 \%-$ $9.3 \%)$.

When asked if they had a mechanism "to ensure that patients with positive FOBT results complete initial follow-up testing," $62.2 \%$ (95\% CI, 58.9\%-65.3\%) responded affirmatively. It was not possible to tell what proportion of these physicians actually follow their patients to diagnostic test completion as opposed to merely informing them of their positive screening result or scheduling the diagnostic test. Reminder telephone calls were reported by $35.9 \%$ (CI, $33.1 \%-$ $38.7 \%$ ), mailed reminders by $11.5 \%$ (CI, 9.8\%-13.6\%), tracking systems or other office systems by $18.5 \%$ (CI, 16.4\%-20.9\%) and scheduling systems by $15.3 \%$ (CI, 13.0\%-17.8\%).

Table 2. Percentage of Physicians Who Use In-office Fecal Occult Blood Tests ${ }^{a}$

\begin{tabular}{|c|c|c|c|c|c|}
\hline Variable & Physicians, $\mathrm{n}^{\mathrm{b}}$ & Percentages $(95 \% \mathrm{Cl})$ & P Value & Adjusted percentages $(95 \% \mathrm{Cl})^{d}$ & P Value ${ }^{e}$ \\
\hline All & 1134 & $77.8(75.1-80.3)$ & & & \\
\hline Specialty & & & 0.006 & & 0.002 \\
\hline Family practice & 452 & $73.6(68.8-77.9)$ & & $74.2(69.5-78.5)$ & \\
\hline General practice & 61 & $85.1(74.6-91.7)$ & & $75.0(58.6-86.4)$ & \\
\hline Obstetrics-gynecology & 249 & $84.4(80.4-87.6)$ & & $84.8(81.0-87.9)$ & \\
\hline Internal medicine & 372 & $79.1(73.9-83.6)$ & & $79.2(74.0-83.6)$ & \\
\hline Year of medical school graduation & & & 0.009 & & 0.13 \\
\hline $1955-1977$ & 285 & $83.9(78.6-88.0)$ & & $81.9(76.1-86.6)$ & \\
\hline 1978-1985 & 282 & $79.6(73.3-84.7)$ & & $78.9(72.6-84.2)$ & \\
\hline 1986-1994 & 282 & $77.7(72.4-82.2)$ & & $78.7(73.8-82.9)$ & \\
\hline $1995-2002$ & 285 & $70.5(64.1-76.2)$ & & $72.9(66.8-78.3)$ & \\
\hline Number of physicians in practice & & & $<0.001$ & & $<0.001$ \\
\hline 1 & 292 & 87.9 (84.0-90.9) & & $87.1(83.0-90.3)$ & \\
\hline $2-5$ & 472 & $78.5(74.4-82.2)$ & & $79.2(75.1-82.8)$ & \\
\hline $6+$ & 363 & $68.7(63.8-73.2)$ & & $68.8(63.8-73.4)$ & \\
\hline Board Certified & & & 0.05 & & 0.20 \\
\hline Yes & 891 & $76.5(73.3-79.5)$ & & $77.0(73.8-79.9)$ & \\
\hline No & 243 & $82.9(77.3-87.3)$ & & $81.7(75.0-86.9)$ & \\
\hline
\end{tabular}

${ }^{a}$ Data are percentages of physicians who reported using in-office tests only or both in-office and home tests, weighted to account for the survey design

${ }^{b}$ These numbers are the denominators for the percentages

${ }^{c}$ Based on a log-likelihood Chi-square test for association

${ }^{d}$ Based on 1127 physicians in the analysis. Percentages are adjusted for all other variables in the table using predictive margins from a logistic regression model

${ }^{e}$ Based on a global Wald chi-square test for association using a logistic regression model 
Table 3. Percentage of Physicians Who Repeat Fecal Occult Blood Tests after Abnormal Results ${ }^{a}$

\begin{tabular}{|c|c|c|c|c|c|}
\hline Variable & Physicians, $\mathrm{n}^{\mathrm{b}}$ & Percentages $(95 \% \mathrm{Cl})$ & P Value & $\begin{array}{l}\text { Adjusted percentages } \\
(95 \% \mathrm{Cl})^{d}\end{array}$ & P Value ${ }^{e}$ \\
\hline All & 1131 & $17.8(15.8-19.9)$ & & & \\
\hline Specialty & & & $<0.001$ & & 0.67 \\
\hline Family practice & 451 & $16.5(13.3-20.2)$ & & $18.2(14.8-22.1)$ & \\
\hline General practice & 61 & $40.0(28.5-52.8)$ & & $23.0(14.1-35.3)$ & \\
\hline Obstetrics-gynecology & 247 & $19.3(14.8-24.9)$ & & $17.3(13.1-22.6)$ & \\
\hline Internal medicine & 372 & $16.4(12.8-20.7)$ & & $16.7(13.2-21.0)$ & \\
\hline Year of medical school graduation & & & $<0.001$ & & $<0.001$ \\
\hline $1955-1977$ & 284 & $28.5(24.0-33.5)$ & & $25.2(21.0-29.9)$ & \\
\hline $1978-1985$ & 282 & $16.5(11.9-22.3)$ & & $16.3(11.8-22.0)$ & \\
\hline 1986-1994 & 281 & $10.8(7.7-15.1)$ & & $11.6(8.2-16.1)$ & \\
\hline $1995-2002$ & 284 & $15.7(11.7-20.8)$ & & $17.5(12.8-23.4)$ & \\
\hline Number of physicians in practice & & & $<0.001$ & & 0.13 \\
\hline 1 & 291 & $26.0(20.6-32.1)$ & & $22.0(17.0-28.1)$ & \\
\hline $2-5$ & 472 & $15.5(12.7-18.8)$ & & $16.1(13.2-19.5)$ & \\
\hline $6+$ & 361 & $14.0(11.1-17.4)$ & & $15.8(12.6-19.6)$ & \\
\hline Type of FOBT & & & $<0.001$ & & 0.002 \\
\hline Office only & 295 & $24.1(19.6-29.4)$ & & $24.0(19.4-29.3)$ & \\
\hline Home only & 243 & $10.0(6.6-14.7)$ & & $10.7(6.9-16.1)$ & \\
\hline Both & 593 & $18.0(15.5-20.9)$ & & $17.5(14.9-20.4)$ & \\
\hline Board Certified & & & $<0.001$ & & 0.004 \\
\hline Yes & 888 & $14.8(12.7-17.3)$ & & $15.7(13.3-18.3)$ & \\
\hline No & 243 & $29.3(23.7-35.8)$ & & $25.1(19.5-31.7)$ & \\
\hline
\end{tabular}

${ }^{a}$ Data are percentages of physicians who recommended repeating the FOBT after positive FOBT result, weighted to account for the survey design. FOBT = fecal occult blood test

${ }^{b}$ These numbers are the denominators for the percentages

${ }^{c}$ Based on a log-likelihood Chi-square test for association

${ }^{d}$ Based on 1124 physicians in the analysis. Percentages are adjusted for all other variables in the table using predictive margins from a logistic regression model

${ }^{e}$ Based on a global Wald chi-square test for association using a logistic regression model

\section{DISCUSSION}

Colorectal cancer screening patterns have changed dramatically since 2000 , with most primary care physicians now recommending both FOBT and colonoscopy to their averagerisk patients. ${ }^{20}$ However, the current study shows that, as in 2000 , three-quarters of primary care physicians who recommend FOBT use in-office tests. While FOBT done appropriately is an important screening option, in-office FOBT may be worse than no screening at all because it misses $95 \%$ of cases of advanced neoplasia, giving many patients a false sense of reassurance. ${ }^{17,18}$

At the time of the 2000 survey, it had not been possible to distinguish in-office from home tests by Current Procedural Terminology $(C P T)$ coding. In response to our earlier findings, CDC joined with the American Cancer Society (ACS) and other organizations to recommend changing the coding for FOBT so that the two types of test could be distinguished. The revised CPT code, which specifies that the patient was provided three single cards or single triple card for consecutive collection, was introduced in January $2006 .^{24}$ Since January 2007, the Medicare program reimburses for colorectal cancer screening with FOBT only when this new code is used. $^{28}$

Despite published evidence of low accuracy, and the change in $C P T$ codes to reinforce appropriate use of FOBT, our survey results provide no evidence of a shift away from the use of in-office tests. Changes in longstanding practice and accurate use of new codes may require more time than has elapsed between the coding changes and our survey. Physi- cians may use the in-office test because they are frustrated with poor patient compliance with home tests and feel that in-office testing is better than no screening at all. Instead, they should direct more effort toward encouraging patients to complete the home test. ${ }^{18}$ Both patient and provider reminder systems have been shown to be effective in increasing adherence ${ }^{29,30}$ but were reported by only a minority of physicians in our survey. Frequent use of inoffice tests by obstetrician-gynecologists probably reflects the fact that they routinely perform digital rectal examinations as part of the pelvic examination and thus the in-office test is easily accomplished. Since late 2006, the American College of Obstetricians and Gynecologists specifically recommends against the use of in-office tests for colorectal cancer screening. ${ }^{31}$

As in 2000, most physicians in the current survey reported using standard guaiac-based tests, such as those used in the randomized trials, rather than the newer guaiac tests or fecal immunochemical tests. These newer tests generally have been shown to have higher sensitivity for colorectal cancer and advanced lesions than the standard guaiac test, although the specificity of the high-sensitivity guaiac test appears to be lower than that of standard guaiac and at least some of the immunochemical tests. ${ }^{32}$ The recent guideline developed jointly by the ACS, the Multi-Society Task Force on Colorectal Cancer, and the American College of Radiology explicitly recommends that screening should be limited to tests that have single-application sensitivity for cancer $>50 \%$, thus excluding standard guaiac tests as an acceptable option. ${ }^{9}$ The decision analysis recently performed for the U.S. Preven- 
tive Services Task Force suggests that the number of lifeyears gained will be greater with screening strategies that use either the extra-sensitive guaiac or the immunochemical tests than with the standard guaiac test ${ }^{23}$ and the 2008 recommendation from the U.S. Preventive Services Task Force specifies screening with high-sensitivity FOBT. ${ }^{8}$

In addition to offering higher sensitivity, the immunochemical tests may be more acceptable to patients because they do not require dietary restriction and the sample collection methods for some of the tests are designed to be more userfriendly, requiring fewer samples or less direct handling of stool. ${ }^{33,34}$ Medicare began covering immunochemical tests in 2004 , making them a viable option. In our study, almost $40 \%$ of physicians reported not knowing about the effectiveness of the immunochemical tests. Although more research is needed to clarify the comparative performance characteristics of the various FOBTs, education is needed to increase physician awareness of available information about the performance of the newer stool tests.

One area of some improvement identified by this study is that fewer physicians are recommending repeating the FOBT following a positive initial test. In the earlier survey, nearly $30 \%$ of physicians recommended repeating the FOBT as the initial follow-up step to a positive FOBT, rather than immediately recommending total colon examination as suggested in national guidelines. ${ }^{16}$ We could not tell in the earlier survey if some of these physicians recommended diagnostic work-up even if the second sampling yielded negative results. In the current survey, $17.8 \%$ of physicians recommended repeating the test and, of these, only $28.8 \%$ reported stopping the workup if the second test is negative. It is not clear why some physicians repeat the FOBT after a positive test if they continue with the diagnostic work-up regardless of the result of the second FOBT.

The current survey also shows that most physicians now recommend colonoscopy for the diagnostic work-up, a marked improvement since the earlier survey, when almost one-third recommended sigmoidoscopy, which can miss many polyps and cases of cancer. ${ }^{16}$ This change likely reflects the recent shift from sigmoidoscopy to colonoscopy. ${ }^{11,20,35,36}$

Studies of patients with positive FOBTs have documented that many such patients do not receive any follow-up of their positive test. ${ }^{16,37,38}$ A common reason found for lack of followup is that the patient had undergone colonoscopy within the previous few years. ${ }^{37,38}$ Indeed, the use of FOBT within 5 years of a negative colonoscopy is discouraged ${ }^{39,40}$ because of the low yield of significant lesions after recent screening colonoscopy in average-risk patients. However, a recent survey of gastroenterologists in New Haven County, Connecticut found that the majority recommend annual FOBT beginning 1 to 5 years after a normal screening colonoscopy. ${ }^{41}$ In our survey, for physicians who recommended more than one test modality, the precise patterns of use of the multiple modalities are unknown. It may be that some of the physicians who recommend both FOBT and colonoscopy for screening may order or perform FOBT during the interval between colonoscopies. Physician education is needed on the appropriate indications for FOBT, since interim FOBT after a normal colonoscopy is not supported by the evidence and not endorsed by any organizational guidelines.

A limitation of this study is that the survey relies on selfreports and has not been validated. To the extent that physicians overreport correct behavior, our results may underestimate the proportions of physicians who recommend inappropriate practices.

\section{CONCLUSION}

Although FOBT is an important option for colorectal cancer screening, our study suggests that its potential to save lives is not currently being realized because many physicians are continuing to use inappropriate implementation methods. Intensified efforts to inform physicians of recommended technique and promote the use of systems for tracking test completion and follow-up are needed.

Funding/Support: This study was funded by NCI contract NO2-PC51308, CDC inter-agency agreement Y3-PC-6017-01 and AHRQ inter-agency agreement Y3-PC-5019-01 and Y3-PC-5019-02.

Disclaimer: The findings and conclusions in this report are those of the authors and do not necessarily represent the official position of the Centers for Disease Control and Prevention, the National Cancer Institute, or the Agency for Healthcare Research and Quality.

Conflict of Interest: None disclosed.

Open Access This article is distributed under the terms of the Creative Commons Attribution Noncommercial License which permits any noncommercial use, distribution, and reproduction in any medium, provided the original author(s) and source are credited.

Corresponding Author: Marion R. Nadel, PhD; Division of Cancer Prevention and Control, Centers for Disease Control and Prevention, 4770 Buford Highway, MS K55, Atlanta, GA 30341, USA (e-mail: mrn1@cdc.gov).

\section{REFERENCES}

1. Eddy D. American Cancer Society report on the cancer-related health checkup. CA Cancer J Clin. 1980;30:193-240.

2. U.S. Preventive Services Task Force. Guide to Clinical Preventive Services. 2nd ed. Alexandria, VA: International Medical Publishing; 1996.

3. Winawer SJ, Fletcher RH, Miller L, et al. Colorectal cancer screening: clinical guidelines and rationale. Gastroenterology. 1997; 112:594-642.

4. Byers T, Levin B, Rothenberger D, Dodd GD, Smith RA. American Cancer Society guidelines for screening and surveillance for early detection of colorectal polyps and cancer: update 1997. American Cancer Society Detection and Treatment Advisory Group on Colorectal Cancer. CA Cancer J Clin. 1997;47:154-60.

5. U.S. Preventive Services Task Force. Screening for colorectal cancer: recommendation and rationale. Ann Intern Med. 2002;137:129-31.

6. Smith RA, Cokkinides V, von Eschenbach AC, et al. American Cancer Society guidelines for the early detection of cancer. CA Cancer $\mathrm{J}$ Clin. 2002;52:8-22

7. Winawer $\mathbf{S}$, Fletcher $\mathbf{R}, \mathbf{R e x} \mathbf{D}$, et al. Colorectal cancer screening and surveillance: clinical guidelines and rationale-update based on new evidence. Gastroenterology. 2003; 124:544-60.

8. U.S. Preventive Services Task Force. Screening for colorectal cancer: U.S. Preventive Services Task Force recommendation statement. Ann Intern Med. 2008;149:627-37.

9. Levin B, Lieberman DA, McFarland B, et al. Screening and surveillance for the early detection of colorectal cancer and adenomatous polyps, 2008: a joint guideline from the American Cancer Society, the US Multi-Society Task Force on Colorectal Cancer, and the American College of Radiology. Gastroenterology. 2008;134 (5): 1570-95. 
10. U.S. Cancer Statistics Working Group. United States Cancer Statistics: 1999-2005 Incidence and Mortality Web-based Report. Atlanta: U.S. Department of Health and Human Services, Centers for Disease Control and Prevention and National Cancer Institute; 2009. http://apps.nccd. cdc.gov/uscs/. Accessed February 17, 2010.

11. Shapiro JA, Seeff LC, Thompson TD, Nadel MR, Klabunde CN, Vernon sw. Colorectal cancer test use from the 2005 National Health Interview Survey. Cancer Epidemiol Biomarkers Prev. 2008;17:1623-30.

12. Mandel JS, Church TR, Bond JH, et al. The effect of fecal occult-blood screening on the incidence of colorectal cancer. $N$ Engl $\mathrm{J}$ Med. 2000;343:1603-7.

13. Mandel JS, Bond JH, Church TR, et al. Reducing mortality from colorectal cancer by screening for fecal occult blood. N Engl J Med. 1993;328:1365-71.

14. Hardcastle JD, Chamberlain JO, Robinson MH, et al. Randomised controlled trial of faecal-occult-blood screening for colorectal cancer. Lancet. 1996;348:1472-7.

15. Kronborg $\mathbf{O}$, Fenger $\mathbf{C}$, Olsen $\mathbf{J}$, Jorgensen OD, Sondergaard $\mathbf{O}$ Randomised study of screening for colorectal cancer with faecal-occultblood test. Lancet. 1996;348:1467-71.

16. Nadel MR, Shapiro JA, Klabunde CN, et al. A national survey of primary care physicians' methods for screening for fecal occult blood. Ann Intern Med. 2005; 142:86-94.

17. Collins JF, Lieberman DA, Durbin TE, Weiss DG, Veterans Affairs Cooperative Study \#380 Group. Accuracy of screening for fecal occult blood on a single stool sample obtained by digital rectal examination: a comparison with recommended sampling practice. Ann Intern Med. 2005; 142:81-5.

18. Sox HC. Office-based testing for fecal occult blood: do only in case of emergency. Ann Intern Med. 2005; 142:146-8.

19. Phillips KA, Liang SY, Ladabaum U, et al. Trends in colonoscopy for colorectal cancer screening. Med Care. 2007;45:160-7.

20. Klabunde CN, Lanier D, Nadel MR, McLeod C, Yuan G, Vernon SW. U. S. primary care physicians' colorectal cancer screening recommendations and practices, 2006-2007. Am J Prev Med. 2009;37(1):8-16.

21. DeBourcy AC, Lichtenberger S, Felton S, Butterfield KT, Ahnen DJ, Denberg TD. Community-based preferences for stool cards versus colonoscopy in colorectal cancer screening. J Gen Intern Med. 2007;23(2): 169-74.

22. Allison JE, Sakoda LC, Levin TR, et al. Screening for colorecta neoplasms with new fecal occult blood tests: update on performance characteristics. J Natl Cancer Inst. 2007;99:1462-70.

23. Zauber AG, Lansdorp-Vogelaar I, Knudsen AB, Wilschut J, van Ballegooijen M, Kuntz KM. Evaluating test strategies for colorectal cancer screening: A decision analysis for the U.S. Preventive Services Task Force. Ann Intern Med. 2008;149:659-69.

24. American Medical Association. $C P T^{\mathrm{R}}$ Changes 2006: An Insider's View. Chicago, IL

25. Korn EL, Graubard BL. Analysis of Health Surveys. Wiley Series in Probability and Statistics. New York: Wiley; 1999:126-39.

26. SAS Institute. SAS/STAT 9.1 User's Guide. Cary (NC): SAS Institute; 2004
27. Research Triangle Institute. SUDAAN Language Manual, Release 9.0. Research Triangle Park (NC): Research Triangle Institute; 2004.

28. Centers for Medicare and Medicaid Services. Colorectal cancer: Preventable, treatable and beatable - Medicare coverage and billing for colorectal cancer screening. Medicare Learning Network Matters SE0710. Accessed at www.cms.hhs.gov/MLNMattersArticles/downloads/SE0710.pdf. Accessed February 17, 2010.

29. Baron RC, Rimer BK, Breslow RA, et al. Client-directed interventions to increase community demand for breast, cervical, and colorectal cancers screening. Am J Prev Med. 2008;35(1 Suppl):S34-55.

30. Task Force on Community Preventive Services. Cancer prevention \& control, provider-oriented screening interventions: provider reminders \& recall. http://www.thecommunityguide.org/cancer/screening/provideroriented/reminders.html. Accessed February 17, 2010.

31. American College of Obstetricians and Gynecologists. Routine cancer screening. ACOG Committee Opinion No. 356. Obstet Gynecol. 2006; 108:1611-3.

32. Whitlock EP, Lin JS, Liles E, Beil TL, Fu R. Screening for colorectal cancer: A targeted, updated systematic review for the U.S. Preventive Services Task Force. Ann Intern Med. 2008;149:638-58.

33. Cole SR, Young GP, Esterman A, et al. A randomized trial of the impact of new faecal haemoglobin test technologies on population participation in screening for colorectal cancer. J Med Screen. 2003;10: $117-22$.

34. Levin B, Brooks D, Smith RA, Stone A. Emerging technologies in screening for colorectal cancer: CT colonography, immunochemical fecal occult blood tests, and stool screening using molecular markers. CA Cancer J Clin. 2003;53:44-55.

35. Meissner HI, Breen N, Klabunde CN, Vernon SW. Patterns of colorectal cancer screening uptake among men and women in the United States. Cancer Epidemiol Biomarkers Prev. 2006;15:389-94.

36. Chen $\mathbf{X}$, White MC, Peipens LA, Seeff LC. Increase in screening for colorectal cancer in older Americans: results from a national survey. J Am Geriatr Soc. 2008;56:1511-6.

37. Jimbo M, Myers RE, Meyer B, et al. Reasons patients with a positive fecal occult blood test result do not undergo complete diagnostic evaluation. Ann Fam Med. 2009;7:11-6.

38. Rao SK, Schilling TF, Sequist TD. Challenges in the management of positive fecal occult blood tests. J Gen Intern Med. 2009;24(3):356-60.

39. Winawer SJ, Zauber AG, Fletcher RH, et al. Guidelines for colonoscopy surveillance after polypectomy: A consensus update by the US MultiSociety Task Force on Colorectal Cancer and the American Cancer Society. CA Cancer J Clin. 2006;56:143-59.

40. Lieberman D, Nadel M, Smith RA, et al. Standardized colonoscopy reporting and data system; report of the Quality Assurance Task Group of the National Colorectal Cancer Roundtable. Gastrointest Endosc. 2007;6:757-66.

41. Rossi R, Sosa JA, Aslanian HR. Screening colonoscopy and fecal occult blood testing practice patterns: A population-based survey of gastroenterologists. J Clin Gastroenterol. 2008;42:1089-94. 